Journal of Engineering and Applied Sciences 14 (3): 789-795, 2019

ISSN: 1816-949X

(C) Medwell Journals, 2019

\title{
Increased Corrosion Resistance of Stainless Steel 3161 Coated with Nanogold Layers in Simulated Body Fluid (Hank's Solution)
}

\author{
1, 2, ${ }^{3}$ Hussein Sabea Amnas, ${ }^{1,2,3}$ Murtdha Adhab Siyah, ${ }^{2,3}$ Rostam Moradian and \\ ${ }^{2,3}$ Iraj Manouchehri \\ ${ }^{1}$ Ministry of Higher Education Science and Technology, Baghdad, Iraq \\ ${ }^{2}$ Department of Physics, Faculty of Science, Razi University, Kermanshah, Iran \\ ${ }^{3}$ Nanoscience and Nanotechnology Research Centre, Razi University, Kermanshah, Iran
}

\begin{abstract}
This study aimed to increase the corrosion resistance of Stainless Steel 316 (SS31 ๔) alloy used in surgical implants and biomedicine by coating the alloy with nanogold layers. The morphology, particles size and thickness of the gold coating were investigated by Scanning Electron Microscopy (SEM). Results showed that the homogeneity of the coating layer increased after heat treatment. Cross-section SEM images revealed that the SS316L alloy substrate was coated with a gold layer having a thickness of $1.46-2.34 \mu \mathrm{m}$. The particle size of the gold coating was $<20 \mathrm{~nm}$ and prepared by direct-current magnetron sputtering. X-ray diffraction analysis of the samples coated with nanogold after heat treatment showed that the coating layers were crystalline and that the diffraction peaks can be indexed to the face-centred cubic crystalline phase of $\mathrm{Au}$. Finally, results of the potentiodynamic polarisation curves of SS31 6 samples coated with gold layer showed high resistance to corrosion. The corrosion rate decreased and the sample exhibited noble behaviours and highest resistance to ion attack in SBF (Hank's solution) than SS316L alloy without coating. The sample with the highest resistance to corrosion in SBF was the one coated with gold having a thickness of $2.34 \mu \mathrm{m}$ after heat treatment at $500^{\circ} \mathrm{C}$.
\end{abstract}

$\underline{\text { Key words: Nanogold films, SS316L, biocorrosion, DC magnetron sputtering, treatment, resistance }}$

\section{INTRODUCTION}

The orthopaedic field uses medical-type Stainless Steel (SS) 316 (SS316L) as temporary implants (Kamachimudali et al., 2003; Wang et al., 2014) because SS316L has mechanical properties similar to those of bone mineral, can be easily formed into different shapes and is available at low cost. However, SS316L reportedly corrodes in vivo and releases ions from SS alloy (e.g., iron ( $\mathrm{Fe}$ ), $\mathrm{Cr}$ and $\mathrm{Ni}$ ) (Chew et al., 2012; Tuken, 2006; Chakraborty et al., 2014). Okazakia and Gotohb (2005) investigated 20 cases of SS Charnley hip arthroplasties with implants used for 10-13 years and found an accumulation of a considerably high metal ion levels in the body liquid of the patients compared with that without implant (Okazakia and Gotohb, 2005). In another investigation, 50 unsuccessful indigenous SS alloys used as implants were removed from patients in India after over 4 years. The classification of the unsuccessful implant was based on the location of the implant and ratio of failures: $74 \%$ were in the femoral, $8 \%$ in the knee, $4 \%$ in the tibia, $2 \%$ in the humerus and $6 \%$ in the ulna and radius. More than $90 \%$ of the SS316 implant devices were unsuccessful because of the significant localised corrosion such as crevice and pitting corrosions (Manivasagam et al., 2010), nanogold particles exhibit better properties than those of the micro-size. Nanogold particles have ability to obtain different shapes and particles sizes and their surface conjugation with antibodies is suitable for both selective imaging and photothermal killing of cancer cells because of their biocompatibility with and ideal properties for surface plasma resonance in medical applications (Svorcik et al., 2011; Anselme and Bigerelle, 2006). Increasing the corrosion impedance of implant alloys by coating the surface with thin layers has another advantage of biocompatible modification (Maciej et al., 2012). Currently, nanostructured thin layers deposited on alloys play an important role in different material science and technology applications because of their excellent optical and electrical properties (Schaub et al., 2013). The most widespread applications are nanoelectromechanical and micro-electromechanical systems, electronic textiles, sensors, bioengineering applications, biomedical applications, production of non-linear optical properties and devices for surface-enhanced Raman scattering.

Corresponding Author: Hussein Sabea Amnas, Ministry of Higher Education Science and Technology, Baghdad, Iraq 
Ultrathin layers of gold can be produced using different methods including thermal evaporation (Piscopiello et al., 2008) electrochemical deposition and electrophoretic deposition. Nanoparticles are produced using deposition with pulsed laser, microwave, electrochemistry, thermal heating of evaporated thin layers and electrochemical deposition (Wadul et al., 2015). Although, alloys obtained in this way limit the metalosis phenomenon (the migration of alloying elements into the tissues surrounding the implant) and replacing the cytotoxic elements by biocompatible elements is under research (Kajzer et al., 2008), studied the gold nano layers sputtered with thicknesses 10-15 nm thickness on plastic (PTFE) surface and their changes iatrogenic by post deposition tempering at $100-300^{\circ} \mathrm{C}$ and characterised by atomic force research, alphabetic character potential and X-ray electron spectrum analysis (XPS). The results found vital carbon contamination, presence of change structures on gold-coated discovered in XPS spectra and reduce the surface roughness of gold coating, Maciej et al. (2012) research study introduced the research of gold nanoparticles deposited on a zirconium oxide substrate with a coating thickness of $10 \mu \mathrm{m}$. The results produced a high-quality gold coating with good tolerance of implanted materials and superior biocompatibility. Schaub et al. (2013), prepared the nanogold layer and nanocluster coatings by using heat treatment and evaporation method on glass substrate with various heat treatments at room temperature $\left(300^{\circ} \mathrm{C}\right)$, Piscopiello et al. (2008) studied the deposition of skinny films nano gold on the Ni-Cr-Mo alloy as substrate to provide same nano gold skinny films then studied morphology and corrosion testes for nano gold skinny films deposited on $\mathrm{Ni}$ Cr-Mo alloy, Kajzer et al. (2008) studied the gold nano layers sputtered with thicknesses 10-15 nm thickness on plastic (PTFE) surface and their changes iatrogenic by post deposition tempering at $100-300^{\circ} \mathrm{C}$ and characterised by atomic force research, alphabetic character potential and X-ray electron spectrum analysis (XPS). The results found vital carbon contamination, presence of change structures on gold-coated discovered in XPS spectra and reduce the surface roughness of gold coating.

\section{MATERIALS AND METHODS}

Experimental work: The SS316 alloy was cut into $20 \times 20$ $\mathrm{mm}$ at $4 \mathrm{~mm}$ thickness. The samples were ground using $\mathrm{SiC}$ emery papers in the sequence of $120,180,220,320$, $500,800,1000$ and 1200 grit to obtain a flat and scratch-free surface. The samples were polished using a polish cloth and $0.3 \mu \mathrm{m}$ alpha alumina and washed with distilled water. The polished samples were cleaned with
Table 1: Hank's solution chemical composition (Bidhendi and Pouranvari, 2011)

\begin{tabular}{lc}
\hline Component $(\mathrm{gL})$ & Values \\
\hline $\mathrm{NaCl}$ & 8.00 \\
$\mathrm{KCl}$ & 0.40 \\
$\mathrm{CaCl}$ & \\
$\mathrm{NaHCO}_{3}$ & 0.14 \\
$\mathrm{MgCl}_{2} \cdot 6 \mathrm{H}_{2} \mathrm{O}$ & 0.35 \\
$\mathrm{MgSO}_{4} \cdot 7 \mathrm{H}_{2} \mathrm{O}$ & 0.60 \\
$\mathrm{Na}_{2} \mathrm{HPO}_{4}$ & 0.06 \\
$\mathrm{Gluocse}_{2} 2 \mathrm{H}_{2} \mathrm{O}$ & 0.06 \\
$\mathrm{KH}_{2} \mathrm{PO}_{4}$ & 1.00 \\
$\mathrm{pH}$ & 0.60 \\
& 6.80 \\
\hline
\end{tabular}

acetone. The degreased specimens were washed with deionised water, dried and kept in a dissector over a silica gel pad and used for DC magnetron sputtering (Table 1).

DC magnetron sputtering of Au films: The gold layers were deposited using DC sputtering onto the SS316L alloy by using a $99.99 \%$ pure gold target ( 2 in. diameter and $5 \mathrm{~mm}$ thick). The SS316 samples were cleaned using ultrasonic baths of cleaning solvent containing ethanol and acetone and dried at room temperature. The pressure was adjusted to $2 \times 10-6$ Torr and sputtering was completed in an argon environment. The sputtering time and power were controlled with constant values during sputtering. The substrate temperature and sputtering pressure system were adjusted to $20 \mathrm{~mA}$ and 5-20 mTorr. Before starting the sputtering process, the gold target was pre-sputtered for $15 \mathrm{~min}$ with a shutter located in between the gold target and the SS316L samples. This shutter was also used to control the deposition time. The target-substrate distance was controlled at $50 \mathrm{~mm}$ during deposition. The system was checked at different values of power and the calibration graph was used to assess the power and time needed to deposit and achieve the best thickness of layer. The deposition conditions were vacuum pressure controlled at $2.8 \times 10^{-7}$ Torr at a rate of $5 \mathrm{~nm} / \mathrm{min}$. Argon gas was used at 20 standards cubic centimetre per minute $(\mathrm{sscm})$ and the pressure during deposition was 4 Torr.

Scanning Electron Microscopy (SEM) analysis: SEM was applied with an operating accelerating voltage of $3.5-10 \mathrm{kV}$ to characterise the deposition morphology and defects of the layers. FSEM Software was used to control the imaging process and determine the particle size, thickness of coatings and element composite. X-Ray Diffraction (XRD) was conducted using a Philips PW 1840 diffractometer (General Electric) with $\mathrm{Cu}-\mathrm{Ka}$ radiation at $\lambda=0.15418 \mathrm{~nm}, 40 \mathrm{kV}, 30 \mathrm{~mA}$ and $20-80^{\circ}$ scan axis range. The sampling step was $0.2^{\circ}$ and speed was $3^{\circ} \mathrm{min}$.

Corrosion testes potentiodynamic polarization: The SS316 alloy was used as a working electrode, the 
Table 2: Energy Dispersive X-ray analy sis (EDX) for of SS316L alloy substrates after coating by Au without heat treatment

\begin{tabular}{|c|c|c|c|c|c|c|c|c|c|c|c|c|c|c|c|}
\hline Elt & Line & Int. & Error & $\mathrm{K}$ & $\mathrm{Kr}$ & W\% & $\mathrm{A} \%$ & $\mathrm{ZAF}$ & Formnal & $\mathrm{Ox} \%$ & $\mathrm{Pk} / \mathrm{Bg}$ & Class & LConf & HConf & Cat\# \\
\hline$\overline{\mathrm{Ti}}$ & $\mathrm{K} \alpha$ & 12.3 & 4.3334 & 0.0047 & 0.0047 & 0.45 & 0.54 & 1.0563 & - & 0.00 & 3.29 & B & 0.42 & 0.48 & 0.00 \\
\hline $\mathrm{Cr}$ & $\mathrm{K} \alpha$ & 185.8 & 4.3334 & 0.1201 & 0.1201 & 11.02 & 12.27 & 1.1041 & - & 0.00 & 28.22 & A & 10.81 & 11.23 & 0.00 \\
\hline $\mathrm{Fe}$ & $\mathrm{K} \alpha$ & 466.1 & 4.3334 & 0.6278 & 0.6278 & 62.30 & 64.59 & 1.0208 & - & 0.00 & 71.71 & A & 61.55 & 63.04 & 0.00 \\
\hline $\mathrm{Ni}$ & $\mathrm{K} \alpha$ & 51.2 & 4.3334 & 0.2137 & 0.2137 & 21.51 & 21.22 & 1.0062 & - & 0.00 & 10.44 & A & 20.74 & 22.29 & 0.00 \\
\hline An & $M \alpha$ & 134.8 & 29.0140 & 0.0337 & 0.0337 & 4.72 & 1.39 & 0.7232 & - & 0.00 & 20.37 & A & 4.62 & 4.83 & 0.00 \\
\hline - & - & - & - & 1.0000 & 1.0000 & 100.00 & 100.00 & 0.00 & - & - & - & - & 0.00 & - & 0.00 \\
\hline
\end{tabular}

Table 3: Energy Dispersive X-ray analysis (EDX) for of SS316 alloy substrates after coating by nano gold with heat treatments at $500^{\circ} \mathrm{C}$ temperature

\begin{tabular}{|c|c|c|c|c|c|c|c|c|c|c|c|c|c|c|c|}
\hline Elt & Line & Int. & Error & $\mathrm{K}$ & $\mathrm{Kr}$ & W\% & $\mathrm{A} \%$ & $\mathrm{ZAF}$ & Formnal & $\mathrm{Ox} \%$ & $\mathrm{Pk} / \mathrm{Bg}$ & Class & LConf & HConf & Cat\# \\
\hline $\mathrm{C}$ & $\mathrm{K} \alpha$ & 23.9 & 15.8233 & 0.0133 & 0.0131 & 2.99 & 12.93 & 0.4377 & - & 0.00 & 31.60 & A & 2.83 & 3.15 & 0.00 \\
\hline $\mathrm{Si}$ & $\mathrm{K} \alpha$ & 40.7 & 28.4826 & 0.0027 & 0.0026 & 0.30 & 0.55 & 0.8927 & - & 0.00 & 6.47 & A & 0.28 & 0.31 & 0.00 \\
\hline $\mathrm{Ti}$ & $\mathrm{K} \alpha$ & 18.4 & 6.0251 & 0.0048 & 0.0047 & 0.45 & 0.48 & 1.0448 & - & 0.00 & 3.32 & B & 0.42 & 0.47 & 0.00 \\
\hline $\mathrm{Cr}$ & $\mathrm{K} \alpha$ & 271.2 & 6.0251 & 0.1193 & 0.1172 & 10.74 & 10.73 & 1.0912 & - & 0.00 & 27.13 & A & 10.57 & 10.91 & 0.00 \\
\hline $\mathrm{Fe}$ & $\mathrm{K} \alpha$ & 685.2 & 6.0251 & 0.6282 & 0.6282 & 61.25 & 56.95 & 1.0076 & - & 0.00 & 68.85 & A & 60.64 & 61.85 & 0.00 \\
\hline $\mathrm{Ni}$ & $\mathrm{K} \alpha$ & 68.5 & 6.0251 & 0.1949 & 0.1949 & 19.26 & 17.04 & 0.9940 & & & 9.27 & A & 18.66 & 19.86 & 0.00 \\
\hline $\mathrm{Au}$ & $\mathbf{M} \alpha$ & 215.9 & 28.4826 & 0.0368 & 0.0368 & 5.02 & 1.32 & 0.7198 & & & 23.27 & A & 4.93 & 5.11 & 0.00 \\
\hline & - & - & - & 1.0000 & 1.0000 & 100.00 & 100.00 & - & - & - & - & - & - & - & 0.00 \\
\hline
\end{tabular}

Bold value are significant

platinum electrode was the auxiliary electrode and the saturated calomel electrode was the reference electrode. The software was used with a potentiostat to investigate the corrosion tests at a scan rate $0.5 \mathrm{mAsec}^{-1}$ performed in electrochemical measurements. The formula of Hank's solution used in the test is shown in Table 1-3 (Bidhendi and Pouranvari, 2011). The Open-Circuit Potential (E OCP), Tafel extrapolation and cyclic polarisation in Hank's solution were adjusted at $37 \pm 1^{\circ} \mathrm{C}$ to match with human body temperature. Corrosion parameters such as potentials (E corr.), corrosion current density (icorr.) and Tafel slopes were obtained from software used with the corrosion device.

\section{RESULTS AND DISCUSSION}

Figure 1 shows the cross-section SEM micrograph of the 1460-1612.17 nm of gold film deposited using DC sputtering on the SS316L alloy substrate without heat treatment and after heat treatment at $500^{\circ} \mathrm{C}$ for $1 \mathrm{~h}$. The homogeneous and uniform nanogold films deposited exhibited a mean particle size of $>20 \mathrm{~nm}$ (Fig. 2a, b). Figure 3 shows the XRD results of the nanogold-coated samples annealed at $400-500^{\circ} \mathrm{C}$ for $1 \mathrm{~h}$. The diffraction peaks can be indexed to face-centred cubic gold crystalline structure (111) dependent on CAS number 7440.57.5 determined from PDF number 04-0784. SS316L alloy peaks for $\mathrm{FeNi}_{3}$ appeared in structure (111) dependent on PDF number 38-0419. The energy dispersive X-ray spectroscopy showed the results of the elemental composition studies (Fig. 4 and 5: Table 2-4). $\mathrm{Au}$ elements had $\mathrm{Au}$ wt.\% equal to $1.39 \%$. In Fig. 5, Au elements had Au wt.\% equal to $5.02 \%$. The analyses of the potentiodynamic polarisation plots of the corrosion behaviour of the SS316L alloy and the samples coated with gold immersed in SBF are shown in Table 3. The (a)

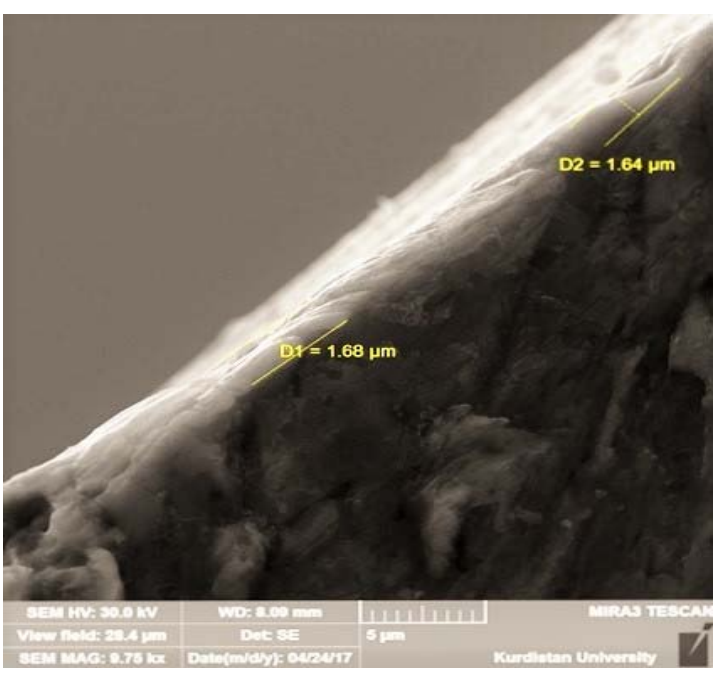

(b)

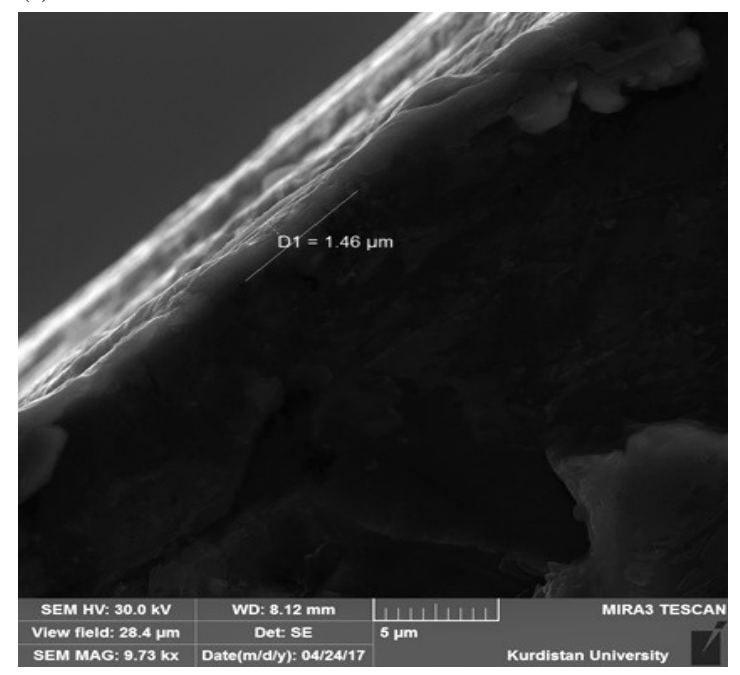

Fig. 1: Cross section SEM images of gold film was deposited on SS316L alloy 

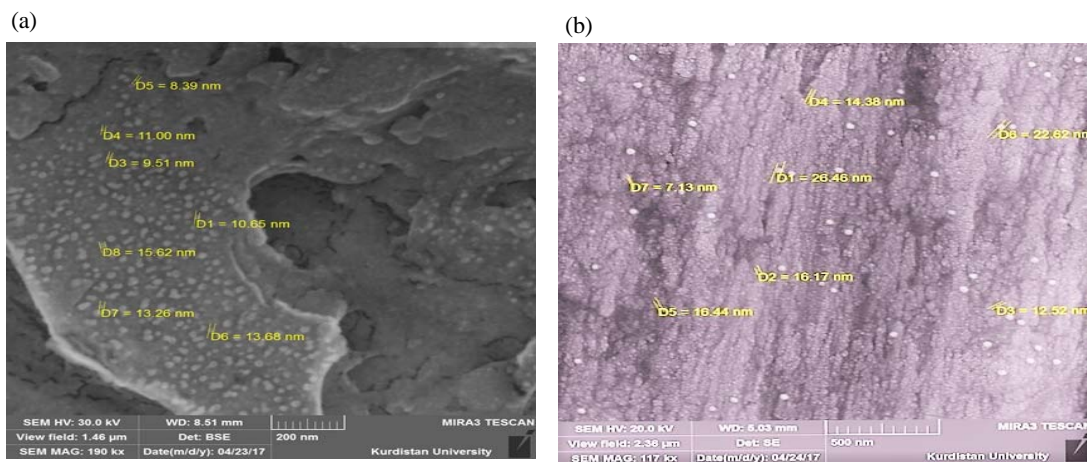

Fig. 2: SEM images of gold film: a) Without heat treatments and b) With heat treatment at $500^{\circ} \mathrm{C}$ was deposited on SS316L alloy

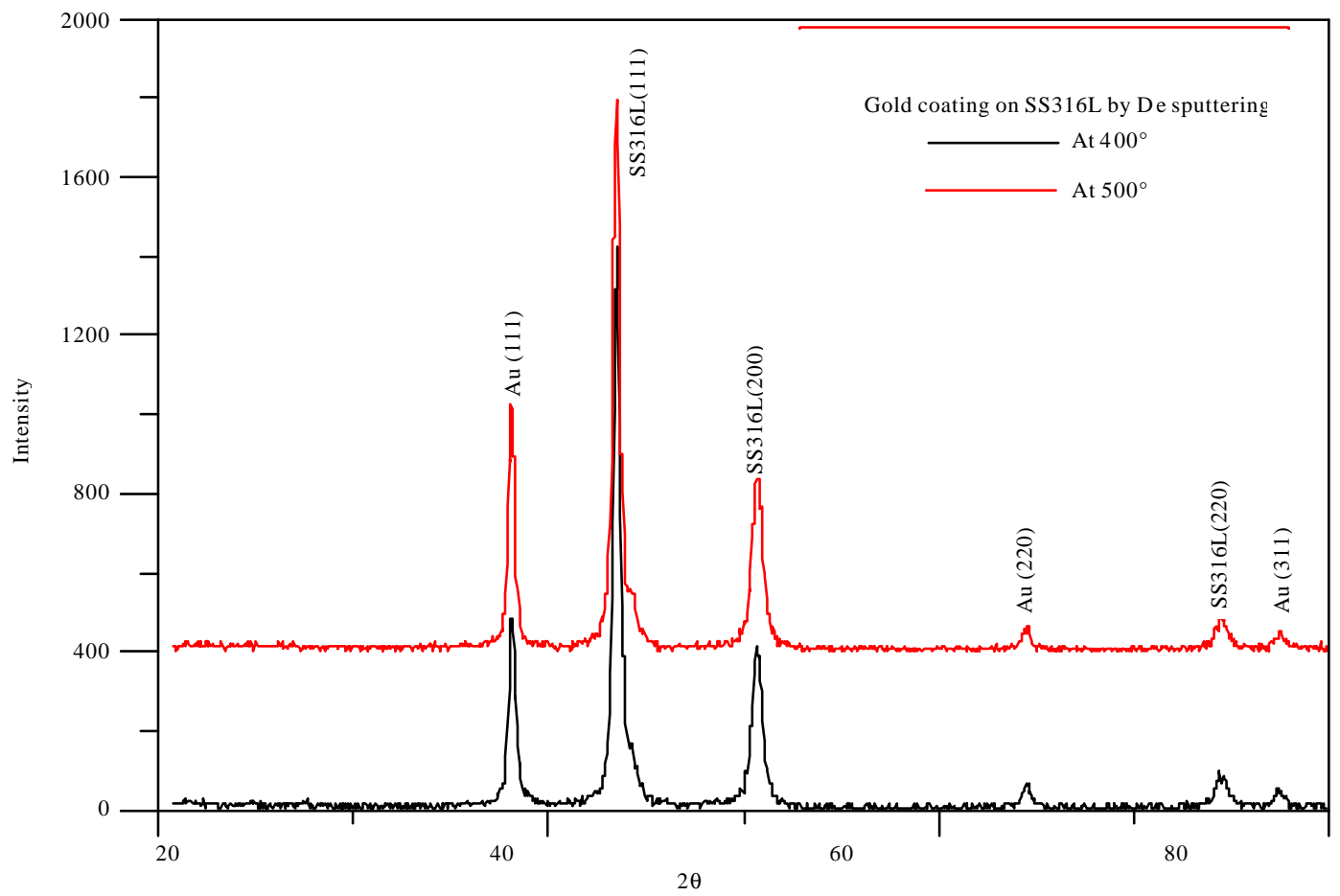

Fig. 3: XRD results of SS31 6 alloy coated with nano gold with heat treatment at $\left(400\right.$ and $\left.500^{\circ}\right)$

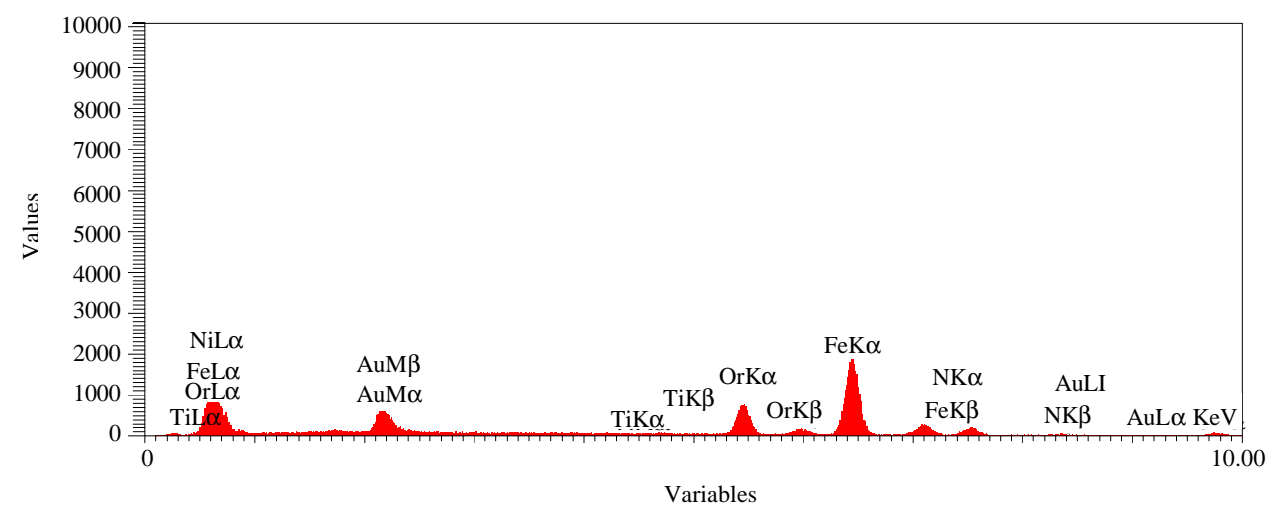

Fig. 4: EDX results of SS316L alloy coated with nano gold at room temperature 


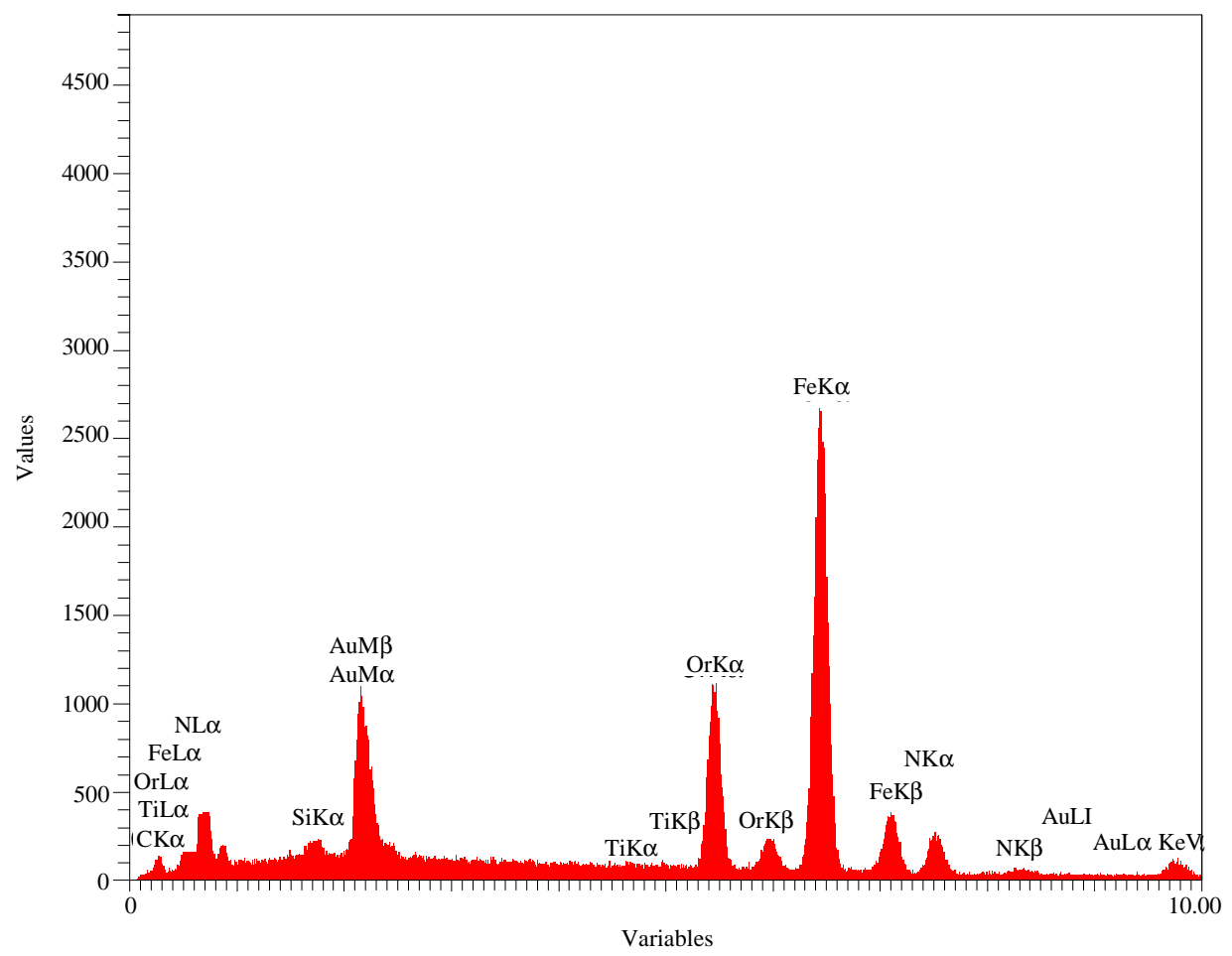

Fig. 5: EDX results of SS316L alloy coated with nano gold with heat treatments at $500^{\circ} \mathrm{C}$ temperature

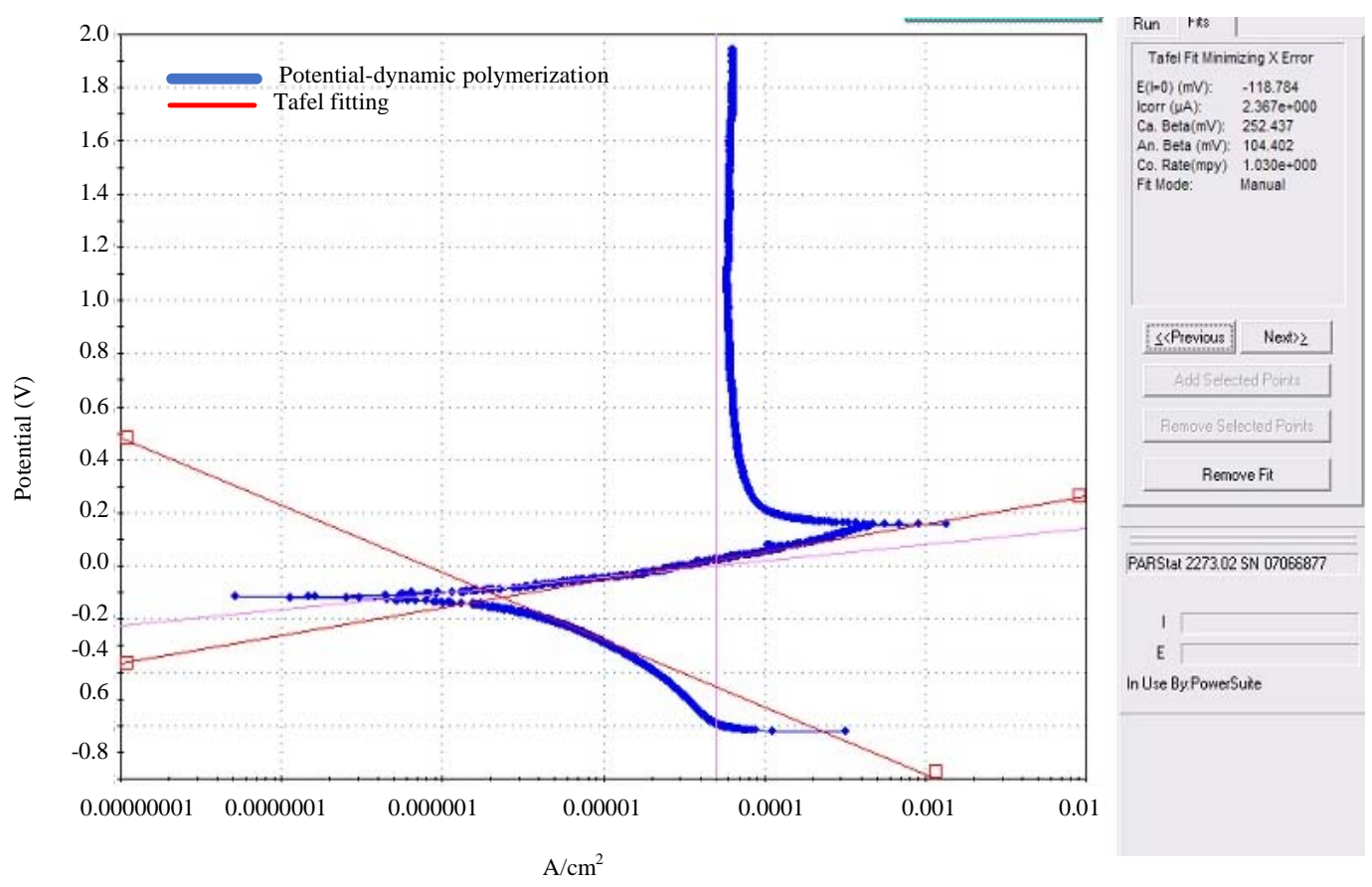

Fig. 6: Corrosion plot of SS31๔ alloy on SBF (Hank solution)

Table 4: Results of electrochemical corrosion tests in Hank solution at $37^{\circ} \mathrm{C}$

\begin{tabular}{|c|c|c|c|}
\hline Sample & $\mathrm{i} \operatorname{corr} \mu(\mathrm{A})$ & Econr & mpy \\
\hline SS316 alloy & 2.3670 & -118 & 1.030 \\
\hline SS31 $L$ alloy coated with Au have $1.4 \mu$ thickness & 0.9806 & -322 & $8.527 \times 10^{-3}$ \\
\hline SS31 $L$ alloy coated with Au have $2.34 \mu$ thickness & 0.7910 & -341 & $6.87 \times 10^{-3}$ \\
\hline
\end{tabular}




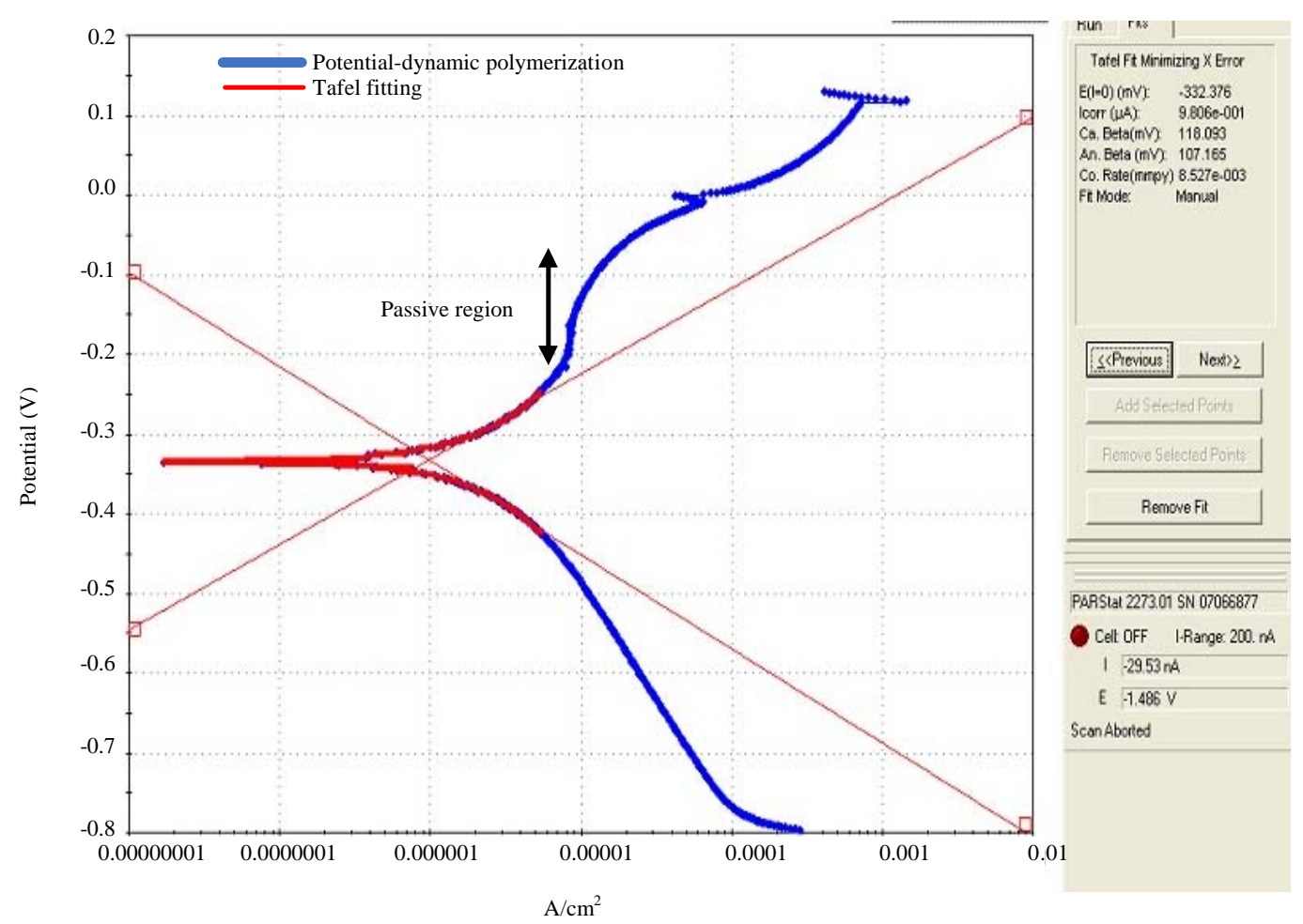

Fig. 7: Corrosion plot of SS31 $\mathrm{L}$ alloy coated with nano gold have $(1.46 \mu \mathrm{m})$ thickness on SBF (Hank solution)

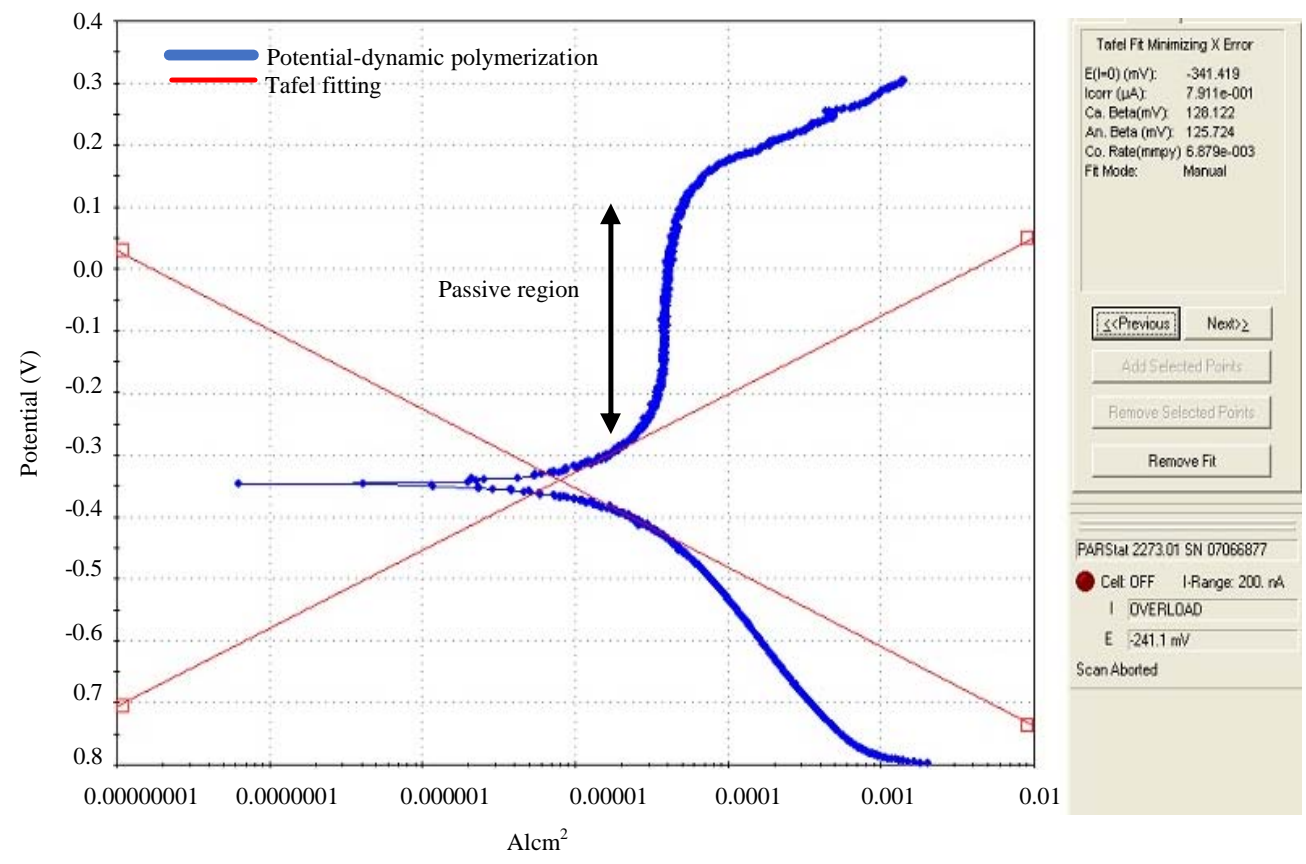

Fig. 8: Corrosion plot of SS31 $\measuredangle$ alloy coated with nano gold have $(2.34 \mu \mathrm{m})$ thickness on SBF (Hank solution)

corrosion tests and potentiodynamic polarisation plots are presented in Fig. 6-8. When the SS316 alloy was immersed in SBF, the corrosion potential was $-118 \mathrm{mV}$.
The corrosion potential shifted to the cathodic side for the samples coated with nanogold with a coating thickness of 1.46 and $2.34 \mu \mathrm{m}$ and the potential values 
were -322 and $-341 \mathrm{mV}$, respectively. The Corrosion Rate (CR) for the SS316L alloy (1.030) in SBF decreased to $8.527 \times 10^{-3} \mathrm{mmPY}$ for the sample coated with $1.46 \mu \mathrm{m}$ gold and decreased to $\left(0.87 \times 10^{-3} \mathrm{mmPY}\right.$ for the sample coated with $2.34 \mu \mathrm{m}$ gold.

\section{CONCLUSION}

The nano gold coating prepared using DC sputtering on the SS316L alloy exhibited excellent crystallinity and homogeneity and the coating diffusion inside the alloy was achieved using heat treatment at $500^{\circ} \mathrm{C}$ for $1 \mathrm{~h}$. The DC sputtering of gold produced coating layers with 1.46-2.34 $\mu \mathrm{m}$ thickness which depended on the time and current values used during sputtering. From the results of potentiodynamic polarisation curves, the SS316L samples coated with gold layer exhibited high resistance to corrosion. The CR decreased with the increase of gold coating thickness. The alloy exhibited noble behaviours and good resistance to ion attack in SBF (Hank's solution) compared with the SS316 alloy without coating. This result indicated that the coating prevented the ion release from the surface of the SS316L alloy which is very important for the successful use of alloys in the biomedical field.

\section{REFERENCES}

Anselme, K. and M. Bigerelle, 2006. Effect of a gold-palladium coating on the long-term adhesion of human osteoblasts on biocompatible metallic materials. Surf. Coat. Technol., 200: 6325-6330.

Bidhendi, A.R.H. and M. Pouranvari, 2011. Corrosion study of metallic biomaterials in simulated body fluid. Metalurgija, 17: 13-22.

Chakraborty, J., S. Sengupta, S. Ray, S. Ghosh and R. Kapoor et al., 2014. Multifunctional gradient coatings of phosphate-free bioactive glass on SS316L biomedical implant materials for improved fixation. Surf. Coat. Technol., 240: 437-443.
Chew, K.K., S.H.S. Zein and A.L. Ahmad, 2012. The corrosion scenario in human body: Stainless steel 316L orthopaedic implants. Nat. Sci., 4: 184-188.

Kajzer, W., A. Krauze, W. Walke and J. Marciniak, 2008. Corrosion behaviour of AISI $316 \mathrm{~L}$ steel in artificial body fluids. J. Achiev. Mater. Manuf. Eng., 31: 247-253.

Kamachimudali, U., T.M. Sridhar and B. Raj, 2003. Corrosion of bio implants. Sadhana, 28: 601-637.

Maciej, B., M. Hajduga and D. Jedrzejczyk, 2012. Analysis of ceramic implants surface with golden nano-layer. J. Metal Czech Republic, 2: 23-25.

Manivasagam, G., D. Dhinasekaran and A. Rajamanickam, 2010. Biomedical implants: Corrosion and its prevention-a review. Recent Pat. Corros. Sci., 2: 40-45.

Okazakia, Y. and E. Gotohb, 2005. Comparison of metal release from various metallic biomaterials In vitro. Biomater., 26: 11-21.

Piscopiello, E., L. Tapfer, M.V. Antisari, P. Paiano and P. Prete et al., 2008. Formation of epitaxial gold nanoislands on (100) silicon. Phys. Rev. B, 78: 035305-1-035305-7.

Schaub, A., P. Slepicka, I. Kasparkova, P. Malinsky and A. Mackova et al., 2013. Gold nanolayer and nanocluster coatings induced by heat treatment and evaporation technique. Nanoscale Res. Lett., 8: 249-256.

Svorcik, V., J. Siegel, P. Sutta, J. Mistrik and P. Janicek et al., 2011. Annealing of gold nanostructures sputtered on glass substrate. Appl. Phys. A, 102: 605-610.

Tuken, T., 2006. Polypyrrole films on stainless steel. Surf. Coat. Technol., 200: 4713-4719.

Wadul, H.M., M.K. Abbass and S.A. Ajeel, 2015. Corrosion of gold thin films deposited by sputtering deposition method. Eng. Technol. J., 33: 1145-1153.

Wang, H., X. Shu, E. Liu, Z. Han and X. Li et al., 2014. Assessments on corrosion, tribological and impact fatigue performance of Ti-and TiN-coated stainless steels by plasma surface alloying technique. Surf. Coat. Technol., 239: 123-131. 